\title{
Research Paper on Design and Implementation of Solid Organic Waste Managing System
}

\author{
Ramesh Prasad Dahal \\ Nepal Science and Technology Research Centre, Kathmandu 44600, Nepal
}

\begin{abstract}
During the energy crisis of the nation and normal day-to-day activities, biogas technology can be a potential alternative source of energy. Conventional biogas has considerably low output methane gas for a given organic input. Considering the need for efficient biogas plant, SOWMS (solid organic waste managing system) has been designed and implemented on a trial basis by constructing community bin at ward number 4 of Gothatar VDC, Nepal. When composition of output biogas from the SOWMS was tested for five times, at different days, the average composition of gas was 55\% methane and 35\% carbon dioxide. The gas produced from $1 \mathrm{~kg}$ of waste is calculated to be 45 liters and $\mathrm{pH}$ value of slurry was found to be 7.8. These values indicate that designed system has good performance and that it can be optimized in the future research. Finally, this research work has some social implications that can have potential impact to uplift the society.
\end{abstract}

Key words: Biogas, SOWMS, digester, leachate, slurry, dome.

\section{Introduction}

Energy crisis is one of the major problems in Nepal. In urban and suburban areas of the nation, people rely heavily on LPG (liquefied petroleum gas) for cooking purpose. Lack of affordable and systematic supply of fossil fuel like LPG has been a major problem for urban people. Time and often, people are suffering from fuel shortage in the market. In the recent energy crisis of Nepal, there was LPG shortage. To fulfill the daily cooking needs, people switched to Induction Cooker. Faults were seen in the local distribution transformer due to the overloading in the peak hours causing substantial loss of money in repair and maintenance [1]. In such situations, biogas can play a major role as an alternative source of energy.

In this connection, this research deals with the design and implementation of SOWMS (solid organic waste managing system) on a trial basis. SOWMS is distinct from conventional biogas plants as it makes the best use of organic waste by producing biogas and compost. It can use not only green plant but also

Corresponding author: Er.Biraj Dhungana, lecturer, research field: mechanical engineering. human urine as the source for producing biogas. Most of the rural settings used woods as the source of energy and SOWMS is highly applicable to those areas that ultimately reduce the dependency of people on firewood hence, minimize deforestation. Slurry could be the best bio-manure for enrichment of soil fertility that increases the crop yield. This reduces the overuse of inorganic fertilizer in low cost for maintaining the soil fertility and crop yield. Hence, SOWMS can enhance the utilization of the organic wastes creating sound environment in better method of solid waste management. Therefore, the SOWMS not only helps to create sound and healthy environment but also gives the effective alternative energy source.

This research work has been implemented by constructing community bin at ward number 4 of Gothatar VDC, an adjoining community of Kathmandu metropolitan city ward number 35. The total population of Gothatar VDC is about 18,000 and total households are about 4,500 [2]. A bin box having the capacity of 5,000 kg at a time has been constructed for the production of alternative energy, biogas from organic waste. In this connection, this research work 
has been playing an enthusiastic positive role in the locality of Gothatar VDC as community waits for this source of alternative energy.

The construction and installation of the plant is completed and is in the phase of further monitoring. With the success of this stage the plant is ready for the use of gas. As this small plant has been implemented on a trial basis, its further development can help to overcome the shortage of LPG in near future. It has created scope for further research and optimization of the design. Further analysis of economy of scale would be beneficial to the community.

The testing of the quantification and qualification of effluent gas could be further done with seasonal changes, varying type and amount of feedstock. The objectives including the production of gas and its distribution, rate of decrease of deforestation, encouraging farmers for using compost instead of chemical fertilizer have been met to some extent as possible. The continuous feeding, monitoring and evaluation of the constructed plant are utmost necessary. The quality and constituent of produced gas tested has given positive result (about 55\% methane) and indication and community will be involved with mutual benefit sharing. However, the success of this phase is that the plant is built and ready for further research.

This research work can help to develop a technology that can be used to generate low-cost energy. This perspective elevates environmental and social factors to the top of the list of criteria relevant to selecting energy supply technologies in long term and short term gains. It rationalizes the possibility that community will choose to pay in monetary terms for such a benign energy source. Interactions between the community members and other scientists have appreciated such source of energy in view of the restricted gas supply and power supply.

\section{Literature Review and Research Gap}

Nepal has over 187,000 house hold size biogas plant and over 300 institutional size plant constructed in some 2,650 out of 3,913 village development committees or municipalities in 68 districts out of 75 districts of Nepal. Plant construction has also recently started in Bajura, Jumla, Manang and Mustang [3].

Annual biogas user's surveys report that around $95 \%$ to $98 \%$ of the house hold size plants constructed under BSP are operating, albeit sometimes with lower level of feeding and gas production. The users survey 2008 reported that around $98 \%$ of the users are satisfied with the performance, $65 \%$ of the plants have toilet connection, $74 \%$ of the users use slurry in one or another form, etc. [4]. The annual rate of plant construction has stagnated around 16,000 in the last 6 to 7 years and even after the armed conflict.

In this growing trend of biogas users, the efficiency of the conventional biogas plants is a major concern. This research work aims to bridge the gap that exists between conventional approach to the design of biogas plants and modern high efficiency requirement of such plants by developing low-cost solution.

SOWMS system incorporates complex design and the use of locally available materials and manpower for construction as shown in Fig 4.

\section{Methodology}

\subsection{Community Participation}

The research work is oriented towards solid waste management of the community at Gothatar VDC-4. It was focused on involving local people in the project. The long-term objective is to motivate people to generate energy from the waste. Community participation helped in creating awareness about economy in waste and steps to overcome energy crisis. A mass meeting was organized and more than 100 local people participated voluntarily. Information on sanitation, economy of waste, alternative energy, biogas plant, and process of installation was disseminated. The experts from UNESCO were also invited during the meeting as guest observers. Local people also voluntarily participated during the 
construction and installation of the plant. People were highly motivated by this research work and they showed interest in raising the project at the community level.

\subsection{Raw Materials for SOWMS}

Organic waste from the community is the major raw material. This includes the waste from local vegetable market, food waste and garbage from household and grass and husk from the fields. Human excreta and livestock's dung can also be utilized along with organic waste of the community. For slurry formation water and urine is required in addition to organic waste. But at present only vegetable waste has been used as input.

\subsection{Installation of Plant and Process Description}

(1) Dome

The PVC water tank, which has replaced the cylinder as mentioned in the proposal, is used for the intake of raw materials i.e. organic wastes, and is called dome. Its $5 \mathrm{ft}$ base has been cut off. The remaining part of the base of width $1 \mathrm{ft}$ from the circumference supports tank to stand on the brick wall with holes of width 5.5 inch below the base of the tank along the circumferences. As the tank is of 2" thickness it is strong enough to withstand the pressure caused due to $5,000 \mathrm{~kg}$ waste.

Fig 1 shows the manhole of the enclosed waste holding chamber which is called Dome.

\section{(2) Digestor Tank}

The tank serves as a reservoir for the slurry feed into the plant. PVC tank of 96 inches diameter is used. The tank is well protected by 9 inches brick wall to the height of $2 \mathrm{ft}$ from the ground level. The space between filter supporting structure and the wall is filled with mud whose temperature is maintained by circulating water. Above the mud level, the space is filled with rice husk that works as insulator and control the temperature of the tank.

Fig 2 shows the construction of Digestor tank being covered by brick wall allowing insulating space in between.

(3) Pressure Divider

It is a pyramidal RCC structure with four stands on the diameter of the dome. Its height is $3 \mathrm{ft}$ from its base. The width of each stand is 16 inch and thickness is 6 inch. It distributes the whole weight of the wastes towards all comers, prevents weight concentration on the copper and mesh and protects the gas collecting pipe.

\section{(4) Copper Filter}

This has to withstand the pressure of the wastes and is more prone to corrosion. So it is made up of thick plates. The fine decomposed materials pass through the copper meshes. The areas of gaps or holes in meshes are in the decreasing order of 3 inch $\times 3$ inch, 2 inch $\times 2$ inch $\& 1$ inch $\times 1$ inch respectively.

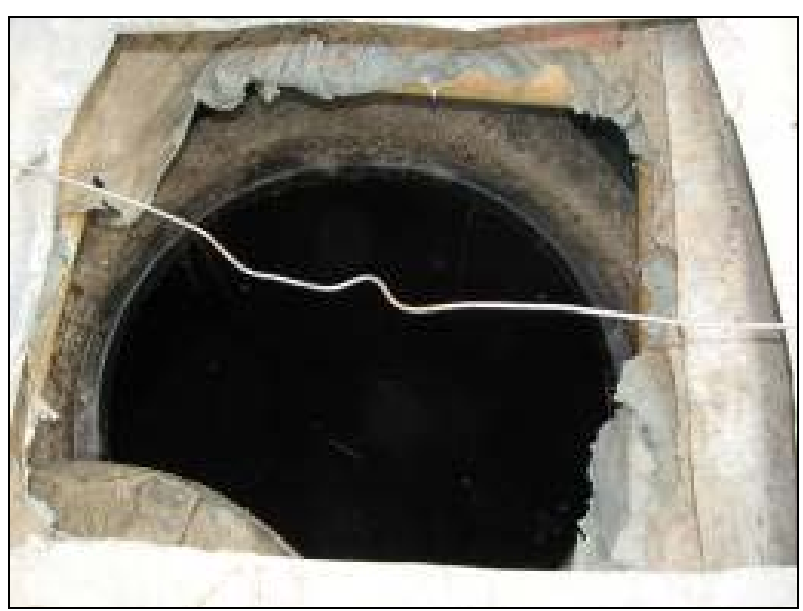

Fig. 1 Dome.

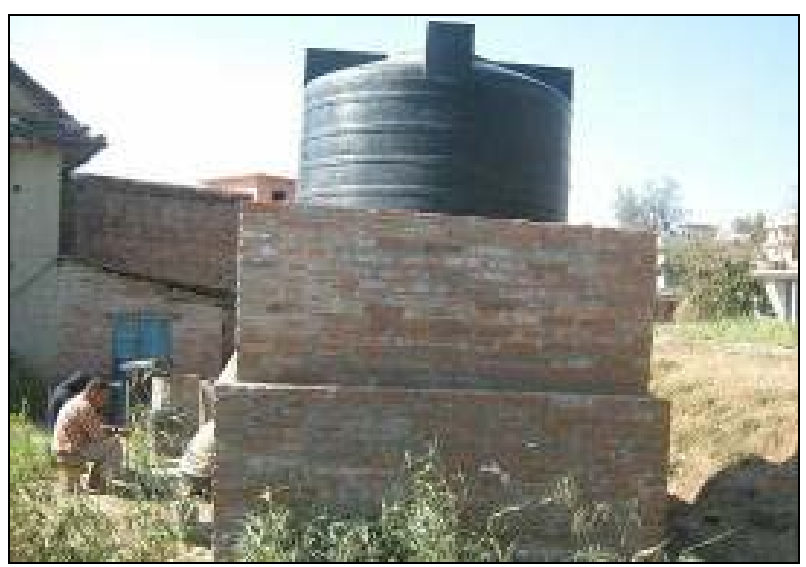

Fig. 2 Digester tank. 
Fig 3 illustrates the top view of conical stand which protects the copper mesh and also houses the chemical dosing pipeline.

(5) Bacteria Breeding Spot

As mentioned earlier there are small holes of size 4 inch $\times 4$ inch made along the diameter of the base of the dome. These holes are filled with mixture of cow dung \& straw prior to filling other organic wastes so as to insure that Methano coccus bacteria (bacteria decomposing organic wastes to produce gas) are readily available.

(6) Gas Outlet Pipe

It is perforated GI pipe (1.5") standing vertically from copper mesh to the top of pressure divider and gets out through the tank and wall to join the collecting tube.

Fig 5 shows the gas collector which is connected to gas outlet pipe through gas regulator as shown in fig 6

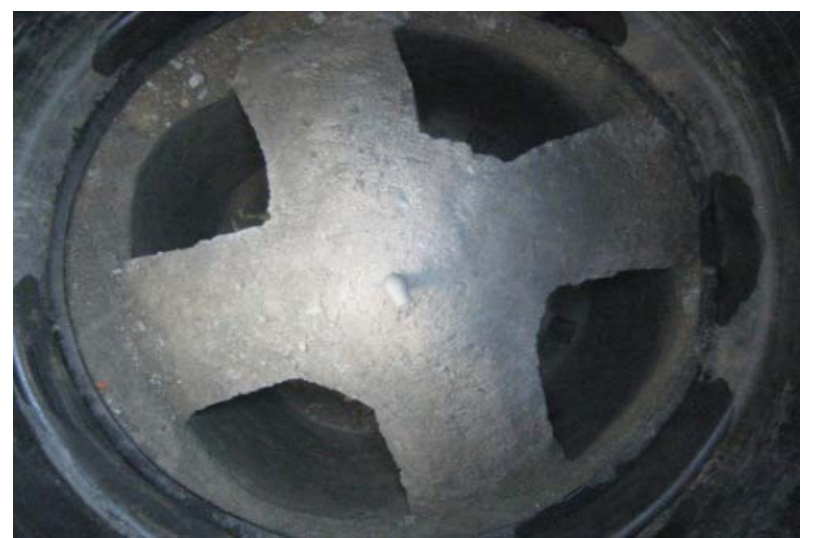

Fig. 3 Pyramid shaped stand on the conical structure supporting gas outlet pipe.

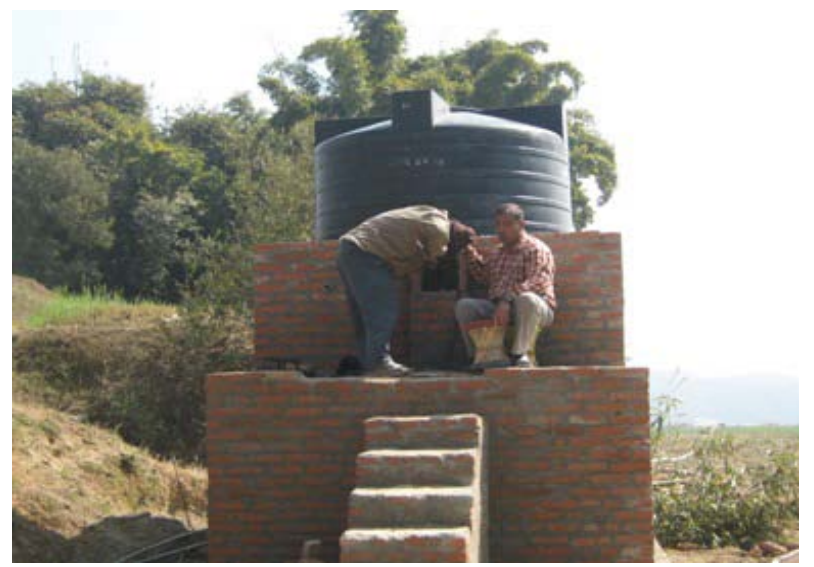

Fig. 4 Plumber fitting gas regulator.

\section{(7) Temperature Maintenance}

Generally, the production of required gas is only observed at the temperature of $35{ }^{\circ} \mathrm{C}$ or more inside the dome. Temperature maintenance is the most essential thing to produce biogas. But it is very difficult to keep the required temperature in winter season. So to maintain the insulation, layers of clay soil $(2 \times 1 / 2 \mathrm{ft})$, coarse sand and husk have been filled in the gap between wall and tank from base of the dome. These materials help to maintain the essential temperature in the cold seasons too. Also sometimes the temperature can be more than required in the extreme hot seasons. A perforated pipe goes round the gap above the layer of clay soil. It brings water to the gap to lower the temperature of it when it is more than required.

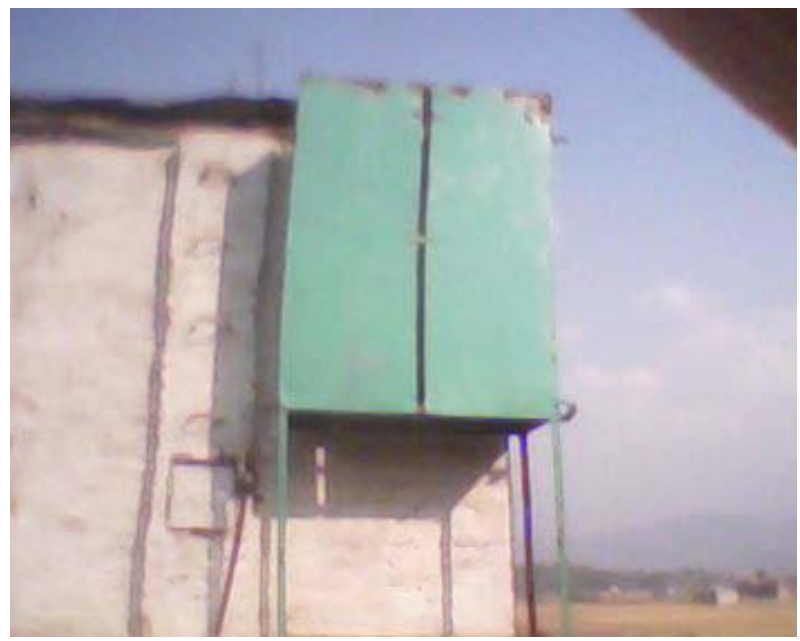

Fig. 5 Gas collector.

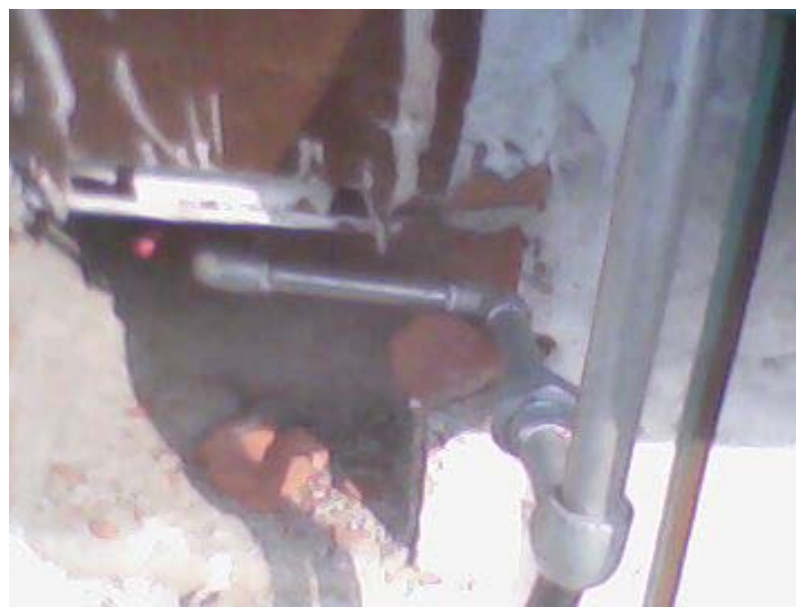

Fig. 6 Gas regulator. 
(8) Gas Collecting Cylinder

The inflammable biogas formed inside the dome is collected by the perforated pipe. Then the collected gas passes through the regulator and gets collected in two rubber tubes. The tube is protected by the iron case. Collection of the gas is detected by upward movement of an indicator fixed with the tube. Then after, the collected gas can be piped for use.

(9) Slurry Outlet Pipe

It lies across the base of the dome at the ground level above the underground tank. It has $4 \mathrm{ft}$ length \& 6 inch diameter and contains "L" shaped sockets of height $3 \mathrm{ft}$ at both ends. It contains two holes of area 3 inch $\times 3$ inch just at centre; areas of some smaller holes, $10 \mathrm{~mm} \times 10 \mathrm{~mm}$, are just below the bigger holes. These holes receive finely decomposed wastes from the copper mesh. The very finely decomposed wastes and leachate pass though the smaller holes to be collected in the tank while larger masses are taken out from one end of the outlet pipe.

\section{(10) Slurry Outlet Container}

As mentioned above, a tank is put just below the outlet pipe. Fine decomposed wastes and leachate get through the perforation in outlet pipe to be collected in the tank. When it gets filled, wastes can be taken out through the same outlet pipe. The use of this container can also help in the formation of gas even though the dome may be empty while cleaning it. If the landscape is feasible i.e. a little steeper, it may not be used too.

(11) Assembly of the Plan

The dome has been constructed as the per landscape. The proposed plan of the project is slightly changed in case of the depth required for slurry outlet and storage of decomposed waste because ground water source was found below not more than five feet. Also, due to the difficulty in making the cylinders of required shapes and sizes as mentioned in the proposal, some changes have been done as per practical purpose. Instead of $20 \mathrm{ft}$ high 48 inch dia. Cylinder, 90 inch wall has been constructed by brick masonry. Cylinder of $20 \mathrm{ft}$ high and 42 inch dia. has been replaced by the water tank of $7 \mathrm{ft}$ high and 72 inch diameter. A water tank of same dimension as mentioned has been put under the ground for the collection of slurry and decomposed wastes.

Central gas collecting cylinder (20 ft high and 6 inch dia.) has been replaced by RCC masonry of $5 \mathrm{ft}$ and 36 inch. A porous pipe of (4 ft high and 1.5 inch dia.) replaces gas collecting cylinder ( $3 \mathrm{ft}$ high and 17 inch dia.) and acts as gas outlet from the central cylinder. Gas storing tube $(5 \mathrm{ft} \times 3 \mathrm{ft} \times 1.5 \mathrm{ft})$ has been transformed to two tubes of $4 \mathrm{ft}$ high. SOWMS's body holder as mentioned in the proposal has been replaced by brick masonry of 14 inch $4 \mathrm{ft}$ high above the ground. Also iron mesh has been replaced by three porous copper plates ( $4 \mathrm{ft}$ dia.) placed at the distance of $1 \mathrm{ft}$. A 6 inch dia. and $20 \mathrm{ft}$ long pipe with $\mathrm{L}$ sockets at the ends has been fitted above the underground tank and below the copper mesh. The pipe allows leachate to go to tank through pores at its center and slurry is taken out through its ends.

Fig. 7 illustrates the sectional view of the Digester indicating its major parts, which are further shown in break down view in Fig. 8.

\section{Operation of the Plant}

The major sources of garbage are households and vegetable market. Human excreta and animal dung can also be fed together with household waste. Total estimated input for the plant at the beginning is

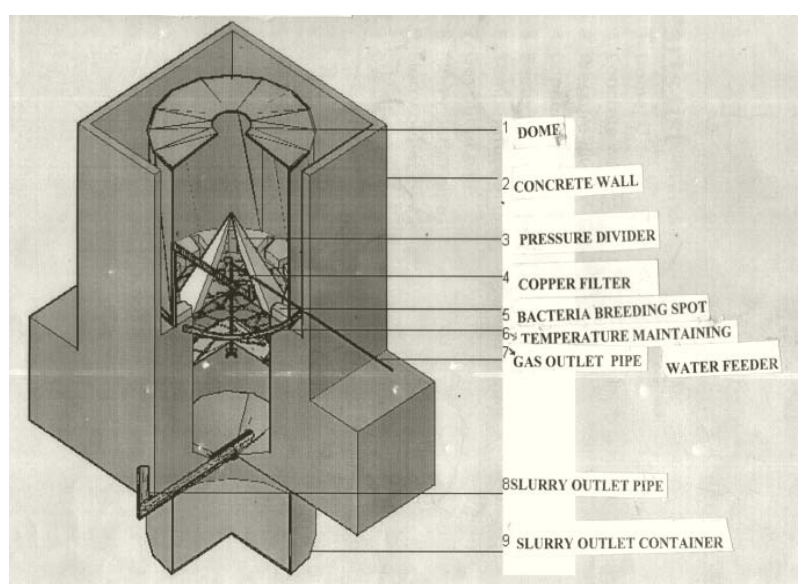

Fig. 7 Construction of the plant. 


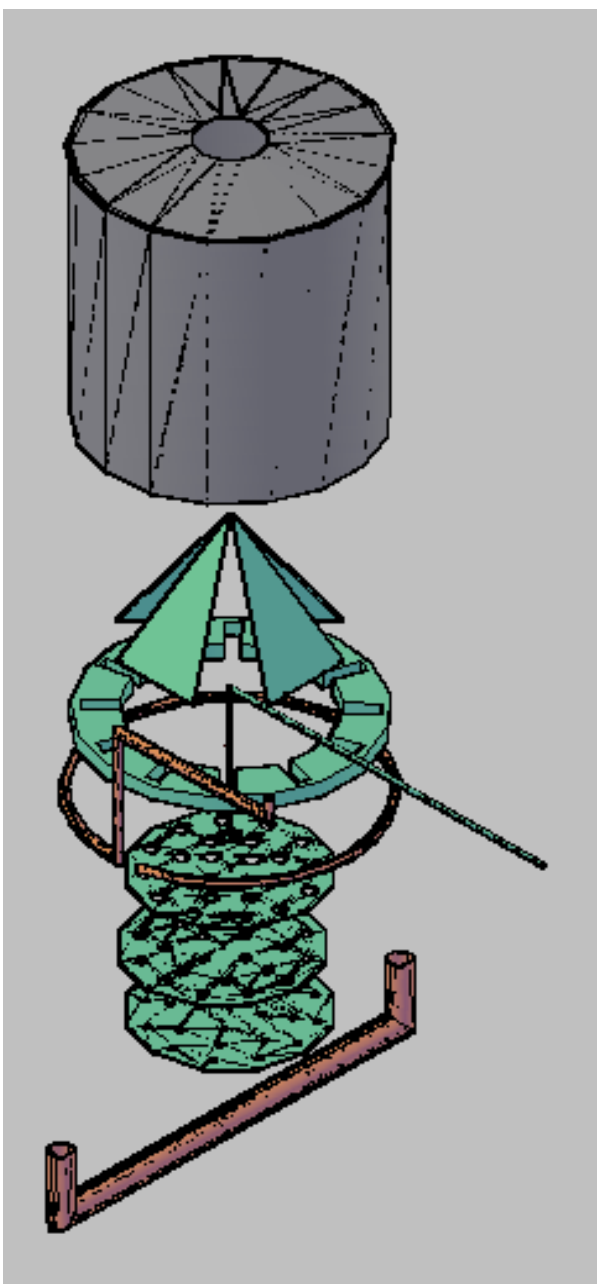

Fig. 8 Perspective inside view of the plant.

6,000-7,000 kg of organic waste. There should be regular feeding of the plant for continuous production of the gas. Appropriate moisture level has to be maintained for efficient operation.

For the operation of SOWMS, the metal cover of dome is opened and then, the collected solid organic waste is kept inside the dome and the lid of dome is closed. The lid of the dome should be air tight to prevent escape of the produced gas. The required temperature inside the dome may be maintained in the summers, but proper insulation has to be done to maintain the favorable temperature in the winters. For this, gap between wall and dome is filled with the layers of insulating materials of clay mud at the lowermost, coarse sand in the middle and husk in the remaining upper part. Also temperature may go up to more than required in the summers. For this a perforated pipe goes round the tank between the gap which carries required quantity of water for the temperature maintenance. This process helps in bacterial activities and breeding inside the plant. Now the input wastes are decomposed by bacterial activities to produce biogas along with some other unwanted gases. The formed gases are collected by a perforated pipe standing below the pyramidal structure which comes out through the tank and wall at $3 \mathrm{ft}$ from the base. The pyramidal structure i.e. pressure divider prevents the damage of copper meshes and also the gas collecting pipe due to the huge weight of the wastes. The finely decomposed wastes pass through the various layers of copper towards bottom of the dome. The decomposed wastes are slowly filtered in three levels by the copper filters (shown as Part 4 in Fig. 7) where gas is produced and is trapped in a pipe. This gas is the output of the plant. Now the filtered slurry passes through the cross section of the outlet pipe from Which the finely decomposed wastes are taken out whereas leachate is collected in the underground tank. When the tank gets filled, leachate can be taken out from the same outlet pipe.

\section{Results and Discussion}

Testing of the components of the system, quantification and qualification of effluent gas could be studied to some extent only due to late production of gas. But the project has further created scope for research and optimization of the design of the plant. The detail scope of the project includes working with the given design of the plant and involvement of the local community in the project to establish the energy use from the waste in the community. In this phase, design, construction and installation of the gas plant have been completed, and some tests were carried out which created the space for further researches in the following areas.

- Direct involvement of community people in waste management; 
- Comparative study of SOWMS and traditional anaerobic digester;

- Comparative study of the efficiency of the plant with anaerobic digesters;

- Type of organic waste to be used for filling the digester and the analysis of quantity and quality of gas extracted.

Initially the $\mathrm{pH}$ value of the substrate inside the new model biogas plant was 4.9. After one month $\mathrm{pH}$ value was increased to 6.2. In gas production period $\mathrm{pH}$ value was found 7.3. When gas was just produced the pressure of the gas was very low, just burning in pipe line. After one week, pressure meter reading was $2 \mathrm{kPa}$. When composition of gas was tested by bio-gas analyzer it was found to be about $54.5 \%$ methane and $34.5 \%$ carbon dioxide. The rest would be sulphur, nitrogen etc. When composition was tested for 5 times, at different days, the average composition of gas was about $55 \%$ methane and $35 \%$ carbon dioxide. The gas produced from $1 \mathrm{~kg}$ of waste is calculated 45 liters and $\mathrm{pH}$ value of slurry was found to be 7.8.

The amount of gas produced has been satisfactory at the moment, but further research and analysis would be needed for better quantitative and qualitative outputs. This could be achieved by continuous monitoring of the plant in future. The amount of feedstock, type of feedstock, seasonal variations could also be monitored as well. The performance of the plant would then be evaluated. The use of biogas would be instrumental in replacing the use of fossil fuels such as fire wood. This would help to decrease deforestations in the community.

Moreover, the slurry from the system could be used as manure after drying. Fully decomposed organic wastes, produced out of this system would be helpful for decreasing the use of chemical fertilizers as this manure increases the fertility of soil, more readily than chemical fertilizers. Now the whole community would be benefitted as they can manage the wastes out of their Households and at the same time get energy out of it. The involvement and participation of the community is an indicator to the success.

\section{Conclusions}

This paper presented the design and implementation of Solid Organic Waste Managing System for the efficient production of biogas. When biogas composition was tested for five times, at different days, the average composition of gas was about 55\% methane and 35\% carbon dioxide. The gas produced from $1 \mathrm{~kg}$ of waste was calculated 45 liters and $\mathrm{pH}$ value of slurry was found to be 7.8. The direct advantage of these figures is that one can obtain more output from same quantity of organic waste as compared to the conventional biogas plants.

Following are the other social implications of this research work:

(1) This project gives enhancement for increasing the awareness through community participation for the benefit of people.

(2) As notified earlier, the avoidance of noxious smell is covered up in the community by the use of this project.

(3) The proper disposal of the solid waste (garbage) leads to sanitation in the colony of human habitat.

(4) The empowerment of un-employed women as a sedentary job especially in younger age groups can partially help them in uplifting the financial source to overcome economic crisis.

(5) This will also give rise to self-respect and self-sufficiency to survive with dignity in community.

(6) The capacity building of the personnel who are involved in such type of activities achieved and enhanced.

(7) This may act as the role model in poor country especially in rural and urban areas where there is adequate land for the project. Young people can be trained for developing such projects, which can improve the financial condition of both individual and country.

(8) Fully decomposed organic wastes, produced out 
of this system can decrease the use of chemical fertilizers as this manure increases the fertility of soil, more readily than chemical fertilizers.

\section{Further Research}

This project is just an initiation and will lead as an example to other people and community to generate energy for day-to-day use. This research can also be expanded in commercial scale and can generate income by selling gas or exchanging with waste. This has eco-friendly approach and is socially acceptable. This project thus can be considered as a sustainable project, however further research is necessary for determining economy of scale.

\section{Acknowledgements}

The author would like to thank UNESCO for providing financial assistance for conducting this research work.

\section{References}

[1] Adhikari, B. 2016. "Design and Testing of DC Powered Induction Cooker.” Master's Dissertation, Lalitpur: Department of Mechanical Engineering, Pulchowk Campus.

[2] CBS. 2014. National Population and Housing Census. Kathmandu: Central Bureau of Statistics.

[3] AEPC. 2010. Biogas Users Survey Report. Lalitpur: Alternative Energy Promotion Center.

[4] AEPC. 2008. Biogas Users Survey Report. Lalitpur: Alternative Energy Promotion Centre. 